\title{
Contribution of directly connected and isolated impervious areas to urban drainage network hydrographs
}

\author{
Y. Seo ${ }^{1}$, N.-J. Choi ${ }^{2}$, and A. R. Schmidt ${ }^{2}$ \\ ${ }^{1}$ Dankook University, Yongin, South Korea \\ ${ }^{2}$ University of Illinois at Urbana-Champaign, IL, USA \\ Correspondence to: Y. Seo (yongwon.seo@gmail.com) \\ Received: 9 April 2013 - Published in Hydrol. Earth Syst. Sci. Discuss.: 2 May 2013 \\ Revised: 15 July 2013 - Accepted: 6 August 2013 - Published: 12 September 2013
}

\begin{abstract}
This paper addresses the mass balance error observed in runoff hydrographs in urban watersheds by introducing assumptions regarding the contribution of infiltrated rainfall from pervious areas and isolated impervious area (IIA) to the runoff hydrograph. Rainfall infiltrating into pervious areas has been assumed not to contribute to the runoff hydrograph until Hortonian excess rainfall occurs. However, mass balance analysis in an urban watershed indicates that rainfall infiltrated to pervious areas can contribute directly to the runoff hydrograph, thereby offering an explanation for the long hydrograph tail commonly observed in runoff from urban storm sewers. In this study, a hydrologic analysis based on the width function is introduced, with two types of width functions obtained from both pervious and impervious areas, respectively. The width function can be regarded as the direct interpretation of the network response. These two width functions are derived to obtain distinct response functions for directly connected impervious areas (DCIA), IIA, and pervious areas. The results show significant improvement in the estimation of runoff hydrographs and suggest the need to consider the flow contribution from pervious areas to the runoff hydrograph. It also implies that additional contribution from flow paths through joints and cracks in sewer pipes needs to be taken into account to improve the estimation of runoff hydrographs in urban catchments.
\end{abstract}

\section{Introduction}

In general, urban drainage systems consist of three parts: the overland surface flow system, the sewer network, and the underground porous media drainage system. Traditionally, no design is considered for the urban porous media drainage part (Yen and Akan, 1999). It is known that the groundwater discharge accounts for the time-delayed recession curve that is prevalent in certain watersheds (Fetter, 2001). This process has not, however, been accounted for satisfactorily modeled by surface runoff models alone (Huber and Dickinson, 1992). The well-known urban hydrology and conveyance system hydraulics model, SWMM has a subsurface flow routing subroutine called GROUND in Runoff Block based on physical processes of groundwater. However, it has a number of parameters for application.

Recently, the connectivity of impervious areas in urban catchments received more attention in terms of hydrologic responses (Lee and Heaney, 2003; Han and Burian, 2009). The impervious areas hydraulically connected to inlets and the route leading directly to a storm water drainage system are referred to as directly connected impervious areas (DCIA) or effective impervious areas (hereafter, DCIA) (Han and Burian, 2009; Roy and Shuster, 2009). This subset of impervious surfaces in urban catchments may be responsible for the majority of stream alteration due to urbanization (Booth and Jackson, 1997; Brabec et al., 2002; Walsh et al., 2005). In this regard, DCIA, which was considered to be a more realistic indicator of urban disturbance, was used in urban hydrologic models instead of total impervious area (TIA). Compared to DCIA, the disconnected or isolated impervious area (hereafter, IIA) was considered not to contribute until excess runoff occurs. It is recognized that the rainfall infiltrating into pervious areas contributes to the river base flow in natural rivers. However, the pervious areas were assumed not to contribute to direct runoff hydrographs until excess rainfall occurs in urban catchments (Boyd et al., 1993; Crobeddu 
et al., 2007; Gironas et al., 2009; Cantone 2010), which was the same with IIA.

However, the infiltrated water takes more complicated flow paths in an urban area than in a rural area, especially with complex sewer systems involved. Butler and Davies (2004) recognized that the infiltrated water in pervious areas also infiltrates back into the sewers and contributes to the measured sewer runoff. Gregory et al. (2006) investigated that soil compaction during the construction of structural foundations can reduce the moisture loss out of the urban hydrologic system and they indicate that this increases the contribution to the runoff hydrograph. Pipe infiltration can be one of the possible flow paths of infiltrated water to the main drainage network. Weiss et al. (2002) investigated 34 combined sewer systems in Germany and found that sewer flow due to infiltration is widely underestimated and more than two thirds of the water passing through the waste water treatment plant can be attributed to infiltration and inflow. De Benedittis and Bertrand-Krajewski (2005) calculated that infiltration and inflow in the sewer system in Lyon, France, can be up to $30 \%$ of the dry weather flow. Vaes et al. (2005) also showed the importance of quantifying the infiltration rate into sewer pipes. These studies emphasize the importance of pervious areas in urban catchments in that they should be treated with greater attention than they are in current practice for hydrologic modeling.

Many researchers have carried out studies on hydrologic response based on the geomorphologic structure of river networks. One of the first efforts to relate the response of a catchment to its geomorphologic characteristics was the geomorphologic instantaneous unit hydrograph (GIUH) (Rodriguez-Iturbe and Valdes, 1979; Gupta et al., 1980). The GIUH demonstrated that when a unit instantaneous impulse is injected into a channel network, the distribution of arrival times at the basin outlet is affected both by the geomorphology of the catchment, such as stream drainage patterns, and the hydraulic characteristics of the channel flow, such as stream roughness (Franchini and O'Connell, 1996).

The GIUH approach takes geomorphologic dispersion into account separately by ordering channel networks according to the Strahler ordering scheme (Strahler, 1957), which is a method of classifying stream segment based on the number of tributaries upstream. In contrast, the width function approach incorporates the width function directly from the network, which captures the unique response of the catchment by representing the topology and the metrics of the channel network in a concise form (Moussa, 2008). The width function is defined as follows (Troutman and Karlinger, 1985): with each point in a channel network we may associate a distance to the outlet of the basin, as measured longitudinally along the channel segments that water will actually follow in reaching the outlet. The width function is typically defined as the catchment area at a distance from the outlet (Moussa, 2008). The width function and the area function can be differently defined based on channelization
(Lashermes and Foufoula-Georgiou, 2007), but the width function basically represents the distance-area function (Lee and Delleur, 1976). The width function approach is considerably simpler than the GIUH approach because it emphasizes the metric representation of the basin instead of the topologic one (Di Lazzaro, 2009). Mesa and Mifflin (1986) and Naden (1992) coupled the width function with the convective diffusion equation to evaluate the hydrodynamic dispersion represented by two parameters, celerity and longitudinal diffusivity. These parameters are dependent on the local slope, discharge and geometry of the channel, which implies that the parameter values can be physically determined (Franchini and O'Connell, 1996). The hydrologic response of a basin should be closely linked to the width function (Gupta and Waymire, 1983) and information about this response might be lost by grouping channel segments (Troutman and Karlinger, 1985).

Although width functions have been applied to rural areas, this study extends their use to urban catchments and further explores the quantification of contribution from pervious and impervious areas composing urban catchments. This paper suggests a framework using the instantaneous unit hydrograph based on the width function (WFIUH) in order to examine the contribution from pervious areas in urban catchments. Utilizing the spatial distribution of imperviousness, this study introduces two types of the width function from pervious and impervious areas, respectively.

As mentioned earlier, this study incorporates the concept of DCIA and IIA to capture the flow characteristics in urban catchments. Lee and Heaney (2003) simulated the runoff hydrographs in urban areas with different methodologies to assess the area of DCIA and showed that the runoff hydrographs can be overpredicted if DCIA is not accurately estimated. IIA defines impervious areas that are indirectly connected to the drainage system and cause flows to be routed through pervious areas before Hortonian excess runoff occurs. DCIA accounts for no additional flow transition between the impervious areas and the network.

The key questions of this paper are (a) to examine applicability of the WFIUH in urban drainage networks, incorporating unique characteristics of urban areas; (b) to investigate the hydrologic contribution of the precipitation infiltrated in pervious areas; and (c) to distinguish the contributions from DCIA, IIA and pervious areas to the flow discharge hydrograph in an urban catchment.

\section{Methodology}

The methodology section is composed of two parts; first, it describes the response function of the main drainage network based on WFIUH. Then, by introducing some assumptions and utilizing the width functions for both pervious and impervious areas, the response function for each land use is 
defined to produce the total response function at the outlet of an urban catchment.

\subsection{Hydrologic response function of the main drainage network based on WFIUH}

Van de Nes (1973) developed a distributed model and proposed a fundamental approach for defining the WFIUH, and derived the celerity and the dispersion coefficient for trapezoidal channel geometry. Naden (1992) suggested an approach based on the width function associated with the solution of the advection-diffusion equation in a natural river basin assuming wide rectangular channel geometry. However, the WFIUH has not been applied to urban drainage networks where finite channel geometry is dominant. In the case of a semi-infinite uniform channel fed by inflow at the upstream $(x=0)$, the routing function is derived from the linear advection-diffusion equation given as follows (Van de Nes, 1973; Naden, 1992):

$$
\frac{\partial Q_{\mathrm{p}}}{\partial t}=D \frac{\partial^{2} Q_{\mathrm{p}}}{\partial x^{2}}-c \frac{\partial Q_{\mathrm{p}}}{\partial x},
$$

where $Q_{\mathrm{p}}$ is the flow perturbation $\left(\mathrm{m}^{3} \mathrm{~s}^{-1}\right), D$ is the diffusion coefficient $\left(\mathrm{m}^{2} \mathrm{~s}^{-1}\right), c$ is the celerity of the flood wave $\left(\mathrm{m} \mathrm{s}^{-1}\right), t$ is time (s) and $x$ is distance from the upstream end (m). Assuming that the drainage network considered in this study consists of pipes with circular cross sections, the celerity and the diffusion coefficient can be derived as follows:

$c=\left[d_{0}\left(1-\cos \theta_{I}\right)-\frac{4}{3} R_{I}\right] \frac{3 v_{I} d_{0}}{4 B_{I}^{2}}$,

$D=C_{1} \frac{Q_{I}}{2 S_{0} B_{I}}$,

where

$C_{1}=1-\frac{F_{I}^{2}}{16}\left[\frac{d_{0}^{2}}{B_{I}^{2}}\left(1-\cos \theta_{I}-\frac{4 R_{I}}{d_{0}}\right)\right]^{2}$,

where $d_{0}$ is the diameter of the circular cross section (m), $v_{I}$ is the initial flow velocity $\left(\mathrm{m} \mathrm{s}^{-1}\right), B_{I}(B=\partial A / \partial y)$ is the initial water surface width $(\mathrm{m}), \theta_{I}$ is the initial angle of the water surface (rad), $R_{I}$ is the initial hydraulic radius (m), $S_{0}$ is the channel slope and $F_{I}$ is the initial Froude number. When the coefficients $D$ and $c$ are constant, the solution to Eq. (1) with the boundary condition $Q(0, t)=\delta(t)$, $Q(x, 0)=0$ and $Q(\infty, t)=0$, is given as follows (Naden, 1992; Franchini and O'Connell, 1996; Da Ros and Borga, 1997):

$u(x, t)=\frac{x}{\sqrt{4 \pi D t^{3}}} \exp \left[-\frac{(x-c t)^{2}}{4 D t}\right]$, where $u(x, t)$ is the impulse response of the advectiondiffusion equation, i.e., the time evolution of the discharge at a distance $x$ from the upstream end when an instantaneous upstream impulse $\delta(t)$ is introduced. With the unit impulse response, $u(x, t)$ given as in Eq. (5), the instantaneous unit hydrograph (IUH) of a catchment can be defined as follows (Da Ros and Borga, 1997):

$h(t)=\int_{0}^{\infty} W(x) u(x, t) \mathrm{d} x$,

where $W(x)$ is the width function normalized by the total network length: the probability that a drop will fall at a flow distance in the interval $[x, x+\mathrm{d} x]$. Then, from Eq. (5) the response from the network for discrete time interval can be written as (Da Ros and Borga, 1997)

$$
h(t)=\sum_{i=1}^{n} \frac{i \Delta x}{\sqrt{4 \pi D t^{3}}} W(i \Delta x) \exp \left[-\frac{(i \Delta x-c t)^{2}}{4 D t}\right] \Delta x .
$$

The diameter and the slope selected to calculate the celerity and the diffusion coefficient of the model are the catchmentrepresentative values to capture the characteristics of the hydrodynamic dispersion. In this study, the flow in the main drainage network is considered to be open channel flow with a circular cross section. The maximum flow rate for the circular cross section occurs at 0.8 of the pipe full depth:

$Q_{\mathrm{o}}=\frac{d_{\mathrm{o}}^{8 / 3} S_{\mathrm{o}}^{1 / 2}}{4 n_{\mathrm{o}}}$,

where $Q_{\mathrm{o}}, d_{\mathrm{o}}, S_{\mathrm{o}}$ and $n_{\mathrm{o}}$ are the peak discharge, diameter, bottom slope and the roughness at the outlet. The flow discharge at each pipe outlet is tested, and if it is greater than the $Q_{0}$, the difference between the actual and the maximum flow is delayed to the next time steps until the flow becomes smaller than $Q_{\mathrm{o}}$.

\subsection{WFIUH for pervious and impervious areas}

In this paper, two width functions from both pervious and impervious areas are utilized to obtain the response function at the catchment outlet. The advantage of using two width functions is that response functions can be distinctively derived for both areas depending on the hydrodynamic properties (transition and diffusion coefficient) of corresponding areas. Moreover, we introduce two assumptions for pervious areas: a portion of infiltrated rainfall contributes to the discharge of the main drainage network (assumption 1) and the remainder of infiltrated water percolates into aquifer, which is eventually lost from the system (assumption 2).

The drainage network and the corresponding width function are obtained at grid level. Figure 1 illustrates the framework of the approach proposed in this study where $n$ represents a grid cell and the main drainage network is represented 


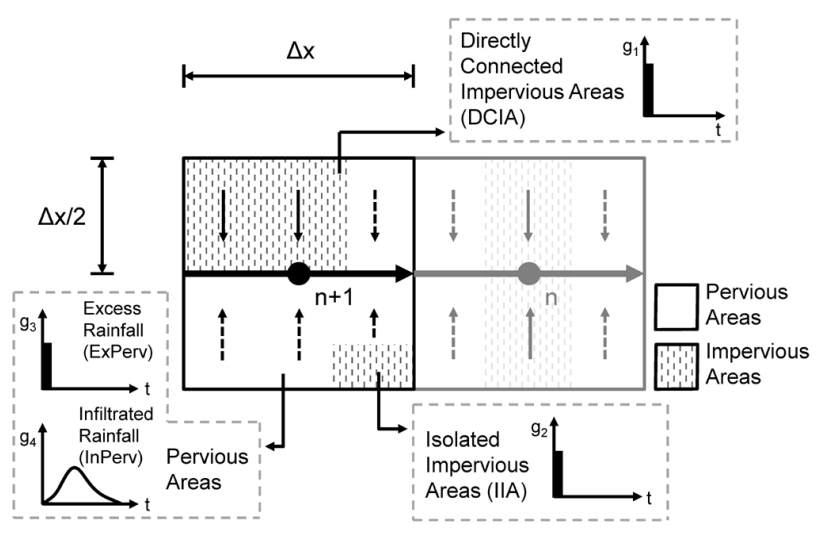

Fig. 1. Response functions from excess rainfall and infiltrated rainfall contributing to runoff hydrographs.

by thick solid arrows. This study utilizes the Green and Ampt method (Green and Ampt, 1911) to estimate the infiltrated amount of rainfall as well as excess rainfall in pervious areas. The excess rainfall falling on impervious areas is assumed to be drained into the main drainage network immediately. Hence, the flow paths for impervious areas are identical to the main drainage network. Paths for pervious areas are divided into two: one for infiltrated and the other for excess rainfall. The first path is subsurface flow induced by the infiltration of rainfall. A portion of the infiltrated rainfall eventually contributes to the main drainage network (assumption 1). The second path taken by excess rainfall from pervious areas is the same as the paths for flows from the impervious areas: the main drainage network. In Fig. 1, DCIA is presented as impervious areas (e.g., roadways and roofs with attached roof drains) where the runoff flows directly into the drainage system. In contrast, IIA is depicted as impervious areas where the runoff does not flow directly into the drainage system. Reduction of DCIA (increasing IIA) is one of the important concepts in land use practice and low impact development (EPA, 2011). In order to account for the different flow paths from pervious and impervious areas, the WFIUH defined by Eq. (6) can be written as follows:

$h_{i}(t)=\sum_{j=1}^{n_{\mathrm{W}}}\left(W_{i}(j \Delta x) \cdot f(j \Delta x, t) \cdot g_{i}(t)\right) \Delta x$,

where $i=1$ for contribution from excess rainfall in DCIA, $i=2$ for excess rainfall in IIA, $i=3$ for excess rainfall in pervious areas (ExPerv), and $i=4$ for infiltrated rainfall in pervious areas (InPerv). $W_{1}$ and $W_{2}$ are the same width functions obtained from the impervious area and $W_{3}$ and $W_{4}$ are the same ones from the pervious area, respectively. $n_{\mathrm{w}}$ is the maximum distance of the width function, $j$ is distance index, $f$ is a response function of the main drainage network, and $g$ is a response function defined in a cell as shown in Fig. 1. From Eq. (5), the response from the main drainage network is given as $f(i \Delta x, t)=\frac{i \Delta x}{\sqrt{4 \pi D_{1} t^{3}}} \exp \left[-\frac{\left(i \Delta x-c_{1} t\right)^{2}}{4 D_{1} t}\right]$,

where $c_{1}$ and $D_{1}$ are the transition and diffusion coefficients of the main drainage network. The response function in a cell, $g_{i}$, is from excess rainfall in DCIA, IIA, and pervious areas (ExPerv).

$g_{i}(t=0)=1$, otherwise $0 ; i=1,2,3$

The response function, $g_{4}$, is from infiltrated rainfalls in pervious areas (InPerv) by assumption 1. Mejia and Moglen (2010) assumed a two-parameter inverse Gaussian travel time distribution for both hillslopes and channels to derive a geomorphologic unit hydrograph for a natural watershed. In this study, $g_{4}$ is assumed to have the same form as Eq. (5), which is a solution of an advection-diffusion equation.

$g_{i}(t)=\frac{\Delta x}{4 \sqrt{\pi D_{2} t^{3}}} \exp \left[-\frac{\left(\Delta x-2 c_{2} t\right)^{2}}{16 D_{2} t}\right] ; i=4$,

where $c_{2}$ and $D_{2}$ are the transition and diffusion coefficients of the flow path, through which the infiltrated rainfall in pervious areas contributes to the main drainage network. Given the total length of $f$ and $g$ as $M_{f}$ and $M_{k}$, respectively, the convolution for discrete time steps can be obtained as

$$
\begin{aligned}
&(f \cdot g)[k] \stackrel{\text { def }}{=} \sum_{m=0}^{\max \left(M_{f}, M_{k}\right)-1} f[m] g[k-m], \\
& 0<k<M_{f}+M_{k}-2 .
\end{aligned}
$$

The response at the outlet can be obtained as the sum of convolution of the response function from each area and the corresponding precipitation.

$Q(t)=\sum_{i=1}^{n_{c}} h_{i} \cdot I_{i}$

Excess rainfall and infiltrated rainfall for corresponding areas are defined in Table 1 , where $I_{\text {imperv }}$ denotes the excess rainfall amount considering depression storage only in impervious areas, $I_{\text {ExPerv }}$ represents the excess rainfall considering depression storage as well as infiltration, and $I_{\text {InPerv }}$ is the infiltrated amount of rainfall. In Table $1, r_{i}$ is the impervious ratio of the watershed and $r_{c}$ is the area ratio of IIA divided by total impervious area. $r_{b}$ is the contributing ratio of infiltrated water to runoff by assumption 2 .

It should be noted that an assumption of an inverse Gaussian travel time distribution is one of many other possibilities. The basic idea is that we extend the response function of the main drainage network, which can be approximated by the solution of the advection-diffusion equation of 
Table 1. Precipitation for each contribution in urban catchments.

\begin{tabular}{lll}
\hline \multirow{2}{*}{ Contribution } & \multicolumn{2}{c}{ Saturation condition } \\
\cline { 2 - 3 } & Before saturation & After saturation \\
\hline DCIA & $I_{1}=\left(1-r_{c}\right) I_{\text {imperv }}$ & $I_{1}=\left(1-r_{c}\right) I_{\text {imperv }}$ \\
IIA & $I_{2}=0$ & $I_{2}=r_{c} I_{\text {imperv }}$ \\
ExPerv & $I_{3}=0$ & $I_{3}=I_{\text {ExPerv }}$ \\
InPerv & $I_{4}=\left(1+\frac{r_{i} r_{c}}{1-r_{i}}\right) r_{b} I_{\text {InPerv }}$ & $I_{4}=r_{b} I_{\text {InPerv }}$ \\
\hline
\end{tabular}

flow perturbation, to that of delayed response of infiltrated water. The solution of the advection-diffusion equation (an inverse Gaussian form of solution) can be a good approximation. Also, it should be noted that the pressurized condition, when conduits are surcharged, is not incorporated in this study. This study left examination of other possible charactersitic response functions as well as more precise hydraulic approaches to take account of pressurized conditions to future study.

\section{Application}

\subsection{Study area}

The test catchment: CDS-51 in this chapter is a part of the Calumet Tunnel and Reservoir Plan (TARP) system in the Chicago area. TARP is a system of deep tunnels and reservoirs that captures combined sewer to relieve pollutant load and combined overflows to waterways in the area. Accurate estimation of the flow is crucial in operation of the entire system. CDS-51 is a highly urbanized catchment, in which most of the drainage load is conveyed through the pipe network as shown in Fig. 2. The watershed captures storm and sanitary flows for a service area of $3.16 \mathrm{~km}^{2}$. The combined sewerage system of CDS-51 collects inflow from in excess of 800 inlets and conveys it to the outlet of the watershed via a network of 722 pipes ranging in diameter from $15 \mathrm{~cm}$ to $2.13 \mathrm{~m}$ in the most downstream area near the outlet. Dry weather flows are intercepted by two interceptor sewers, which convey flow to the Calumet Water Reclamation Plant. When the treatment plant reaches capacity, flow in the largest pipe is directed towards the combined sewer overflow (CSO) location and conveyed through the drop shaft that is located at the outlet of the catchment into the deep tunnel. Table 2 summarizes the diameters, lengths and slopes of the pipe network of CDS-51 according to Strahler's ordering scheme (Strahler, 1957). From 2007 to 2011, the United States Geological Survey (USGS) used three acoustic flow meters to monitor the inflow from the catchment, the volume of flow partitioned to the CSO, and the amount of inflow entering the drop shaft connected to the deep tunnel at CDS-51.

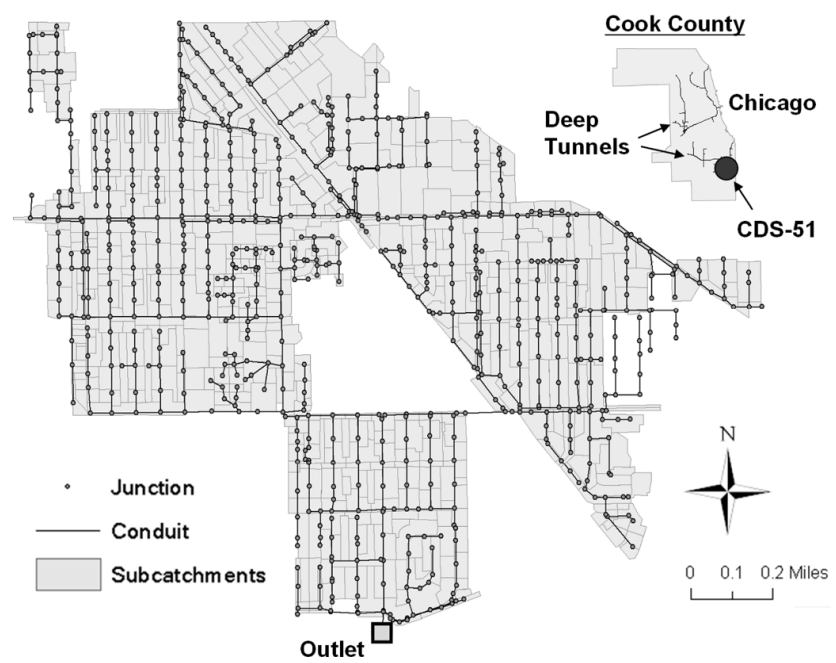

Fig. 2. The drainage pipe network; CDS-51 in Chicago.

\subsection{Detailed impervious map of CDS-51}

One of the advantages of utilizing the width function for the IUH is that it incorporates the spatial distribution of the watershed properties (e.g., imperviousness) that significantly impact the model's estimation capability. The imperviousness ratio is an important factor in urban hydrology modeling. However, it is often given as an average value for one catchment. Imperviousness ratios for subareas within a catchment are typically obtained by assigning impervious values corresponding to the type of land use in the subareas. Crosa-Rivarola (2008) investigated the spatial variability that can be found in urban catchments and made a detailed imperviousness map of CDS-51 based on land use obtained from three different sources and data processing filters: orthoimages with image processing filter, light detection and ranging (lidar) data with lidar filter, and street data with street filter. The final imperviousness map is shown in Fig. 3a. With the imperviousness map explicitly obtained from the orthoimagery, the imperviousness ratio is averaged for each grid cell as shown in Fig. $3 b$.

In this paper, two width functions from pervious and impervious areas are utilized to obtain the response function at the catchment outlet. These width functions are obtained by the fraction of impervious and pervious areas in a given cell and the corresponding drainage network. Figure 4 shows two resulting width functions for pervious and impervious areas obtained from spatial distribution of the imperviousness ratio in Fig. 3b. The width functions in Fig. 4 are normalized by the total network length and presented as distance from the outlet of a catchment. The dashed line in Fig. 4 represents the catchment's average imperviousness ratio; this averaged line was used to divide the width functions for pervious and impervious areas. In CDS-51, the average imperiousness ratio does not greatly differ from the imperviousness ratio from 
Table 2. Conduits of CDS-51 according to the Strahler ordering (Miller et al., 2009).

\begin{tabular}{lrrrrrrrrr}
\hline & & \multicolumn{2}{c}{ Diameter $(\mathrm{m})$} & & \multicolumn{2}{c}{ Length $(\mathrm{m})$} & & \multicolumn{2}{c}{ Bottom slope $\left(\times 10^{-3}\right)$} \\
Order & No. & Mean & Standard dev. & & Mean & Standard dev. & & Mean & Standard dev. \\
\hline 1 & 449 & 0.33 & 0.11 & & 61.62 & 27.72 & & 5.25 & 9.47 \\
2 & 157 & 0.46 & 0.16 & & 59.69 & 29.98 & & 3.70 & 6.01 \\
3 & 57 & 0.72 & 0.23 & & 75.00 & 28.33 & & 1.82 & 2.67 \\
4 & 51 & 1.18 & 0.34 & & 64.30 & 34.54 & & 1.45 & 1.70 \\
5 & 8 & 2.06 & 0.08 & & 98.68 & 7.79 & & 1.56 & 2.05 \\
\hline
\end{tabular}

the detailed map. However, it is possible that using the averaged value can cause uncertainty in the estimation of width functions depending on the spatial distribution of impervious areas.

In this paper, the area of DCIA is estimated from the detailed impervious map developed from orthoimagery (CrosaRivarola, 2008). The average diameter and slope of the drainage network shown in Table 2 are adopted to calculate the hydrodynamic properties of the main drainage network in CDS-51. The celerity, $c_{1}$, and diffusion coefficient, $D_{1}$, used for calculation of the response functions of the main drainage network are calculated by Eqs. (10) and (11) assuming $20 \%$ of the pipe is initially full.

However, the flow path of the infiltrated water to the main drainage network is not explicitly identified for calculation of the delayed response function of pervious area, $g_{4}$ as shown in Fig. 1. The infiltrated rainfall in pervious area takes subsurface flow paths to reach a main drainage network. Therefore, the transition coefficient (celerity) of the flow can be of the same order of the saturated hydraulic conductivity of the soil; in this study $10^{-3} \mathrm{~m} \mathrm{~s}^{-1}$ is used based on the ranges of hydraulic conductivity for pervious areas (Bear, 1988). The two unknown parameters, i.e., the diffusion coefficient for delayed response from infiltrated amount of rainfall, $D_{2}$ in Eq. (21), and the contributing ratio of infiltrated rainfall, $r_{b}$ in Table 1, are calibrated using observed data.

Four sets of observed runoff hydrograph and precipitation data are used in this study as shown in Table 3 . The flow meters and precipitation gages were operated by the USGS from 2007 to 2011 in order to monitor the flow discharge amount into the TARP dropshafts in Chicago. For event 2, during August 2007, four rainfall gages operated by the Illinois State Water Survey (ISWS) surrounding CDS-51 are used because the precipitation records from the USGS gage are unavailable.

\section{Results and discussion}

\subsection{Comparison with the observed flow}

Two coefficients, the transition and diffusion coefficients of infiltrated water, are estimated to maximize the goodness of fit criteria; i.e., the Nash-Sutcliffe model efficiency (Nash
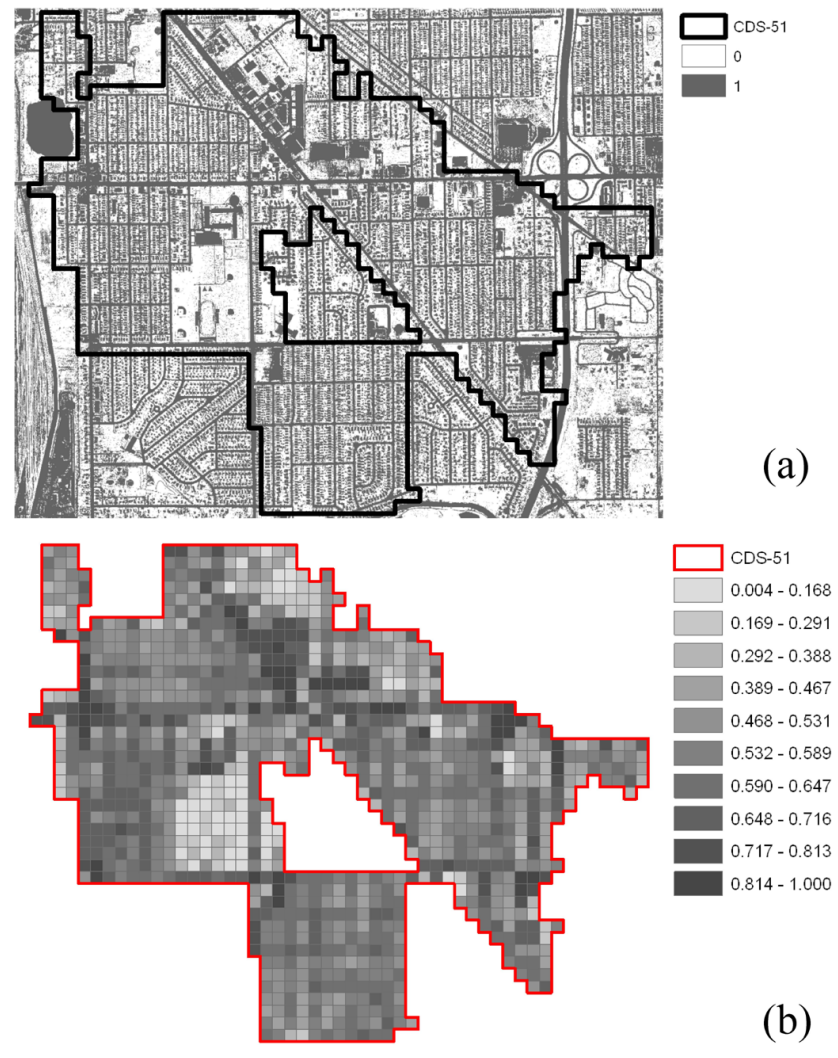

Fig. 3. Imperviousness map of CDS-51 ( 0 for pervious and 1 for impervious area): (a) from orthoimagery (Crosa-Rivarola, 2008), (b) imperviousness ratio averaged to each grid cell.

and Sutcliffe, 1970). Event 3 on January 2008 was used for calibration of parameters. Then, the calibrated values of parameters were used with all other storm events. The NashSutcliffe efficiency, $E$, ranges from $-\infty$ to 1 . If $E$ is close to 1 , the model better simulates the observation.

$E=1-\frac{\sum_{t=1}^{T}\left(Q_{\mathrm{o}}^{t}-Q_{\mathrm{s}}^{t}\right)^{2}}{\sum_{t=1}^{T}\left(Q_{\mathrm{o}}^{t}-\overline{Q_{\mathrm{o}}}\right)^{2}}$,

where $Q_{\mathrm{o}}$ is observed discharge, and $Q_{\mathrm{s}}$ is modeled discharge. Figure 5 shows the location of the estimated values 


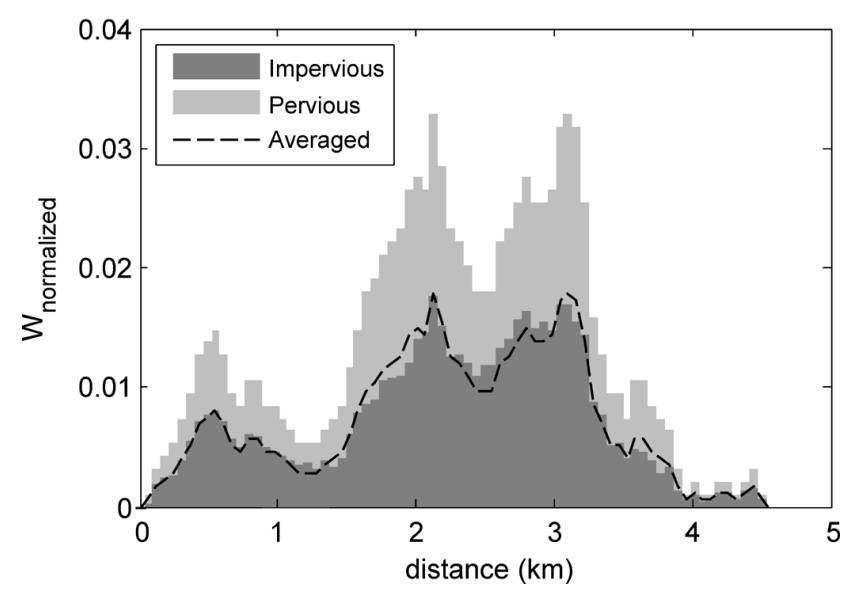

Fig. 4. Two width functions for pervious and impervious areas obtained from the imperviousness map in CDS-51 normalized by the total catchment area.

of unknowns that maximize the model efficiency. The model efficiency indicates how accurately the model reproduces the observed results.

The contributing ratio of pervious area, $r_{b}$, is estimated as 0.55 ; it implies that $55 \%$ of infiltrated water eventually contributes to the runoff hydrograph. The parameter values estimated for CDS-51 are listed in Table 4.

Figure 6 compares the estimated runoff hydrographs from the conventional approach (considering only Hortonian excess runoff and ignoring the contribution of infiltrated rainfall to the main drainage network) and the proposed approach (accounting for both Hortonian runoff and contribution of infiltrated rainfall) with the observed hydrograph. The conventional approach is based on the typical assumption that there is no runoff contribution from pervious areas before saturation to the main drainage network. It also assumes that $100 \%$ of impervious area of the watershed contributes to runoff without distinction between DCIA and IIA. As shown in Fig. 6, the conventional approach shows a mass balance error. For example, if total rainfall amount is $100 \%$ from the January 2008 storm (Fig. 6c), the loss from infiltration is calculated to be $46 \%$, the loss from depression storage is $3 \%$ and the resulting excess rainfall runoff is $51 \%$, which is considerably different to the actual runoff $(70 \%)$ from observations. It implies that part of the infiltrated amount of rainfall can eventually contribute to the runoff hydrograph. Figure 6 also shows improvement in the estimation of the flow hydrograph, especially for the long tail, when the contribution from infiltrated rainfall amount is accounted for; the proposed approach in this study. The goodness of fit is significantly increased when contribution from pervious areas before saturation is taken into account as shown in Table 5. Although the model efficiency, for event 1 is decreased when contribution from pervious areas is considered, the model better simulates the long tail in the hydrograph.
Table 3. Four sets of observed hydrograph and precipitation.

\begin{tabular}{llrll}
\hline Event & $\begin{array}{l}\text { Starting } \\
\text { date }\end{array}$ & $\begin{array}{r}\text { Duration } \\
\text { (h) }\end{array}$ & $\begin{array}{l}\text { Flow data } \\
\text { obtained from }\end{array}$ & $\begin{array}{l}\text { Precipitation } \\
\text { obtained from }\end{array}$ \\
\hline 1 & $2007-04-25$ & 24 & USGS & USGS \\
2 & $2007-08-22$ & 28 & USGS & ISWS \\
$3^{*}$ & $2008-01-07$ & 15 & USGS & USGS \\
4 & $2009-04-27$ & 33 & USGS & USGS \\
\hline
\end{tabular}

* Parameter estimation.

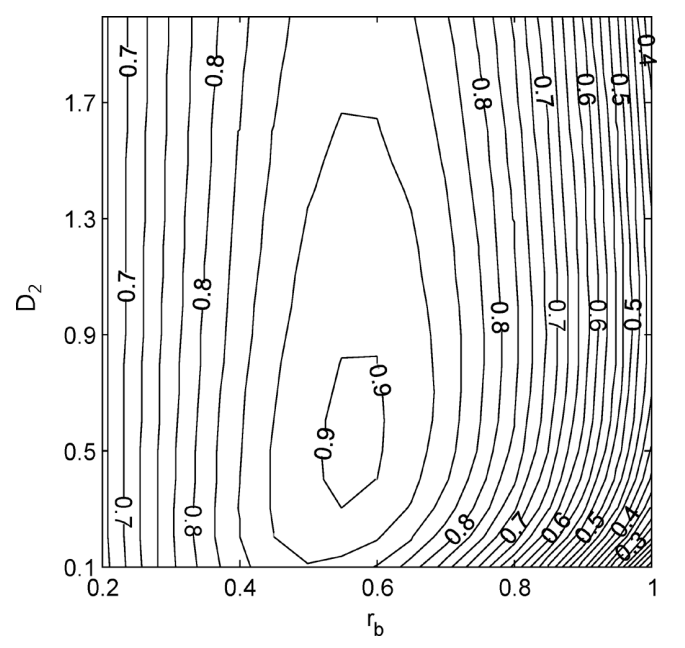

Fig. 5. The model efficiency, $E$, as a function of diffusion coefficient, $D_{2}$, and contributing ratio of pervious area, $r_{b}$.

\subsection{Comparison with other models}

Since most urban drainage systems are modeled using a dynamic pipe simulation program that solves full hydraulics, it is necessary to compare the results with one of these hydraulic modeling approaches and also other hydrologic models. The proposed approach in this study is compared with the results from two different hydraulic and hydrologic modeling approaches: the US Environmental Protection Agency (EPA) Storm Water Management Model (SWMM) and Illinois Urban Hydrologic Model (IUHM) based on GIUH (Cantone et al., 2009; Cantone, 2010). Cantone and Schmidt (2011) compared the results from the detailed SWMM and IUHM and showed the IUHM's ability to predict the hydrograph with much less information compared to SWMM.

Figure $7 \mathrm{a}$ compares the resulting hydrographs from SWMM with the proposed approach in this study. The detailed SWMM of CDS-51 includes complete information of 722 pipes and conduits (Cantone et al., 2009; Cantone, 2010). In contrast, the lumped SWMM consists of one subcatchment and one conceptual conduit. As shown in Fig. 7a, the proposed approach in this study shows better estimates for the hydrographs of CDS-51 compared with the lumped SWMM as well as the detailed SWMM. Compared with the IUHM, the proposed approach shows better estimates in 
Table 4. Parameter values estimated for CDS-51.

\begin{tabular}{lrrrrrrrr}
\hline & & \multicolumn{7}{c}{ Parameters } \\
\cline { 3 - 9 } Catchment & $\begin{array}{r}\text { Area } \\
\left(\mathrm{km}^{2}\right)\end{array}$ & $\begin{array}{r}\Delta x \\
(\mathrm{~m})\end{array}$ & $\begin{array}{r}c_{1} \\
\left(\mathrm{~m} \mathrm{~s}^{-1}\right)\end{array}$ & $\begin{array}{r}D_{1} \\
\left(\mathrm{~m}^{2} \mathrm{~s}^{-1}\right)\end{array}$ & $r_{i}$ & $r_{c}$ & $\left(10^{-1} \mathrm{~m}^{2} \mathrm{~s}^{-1}\right)$ & $r_{b}$ \\
\hline CDS-51 & 3.42 & 156 & 0.43 & 5.58 & 0.54 & 0.23 & 5.6 & 0.55 \\
\hline
\end{tabular}

Table 5. Comparison between a runoff hydrograph considering contribution from impervious areas only and one that considers contribution from both pervious and impervious areas.

\begin{tabular}{|c|c|c|c|c|c|c|c|}
\hline \multirow[b]{2}{*}{ Event } & \multirow[b]{2}{*}{ Date } & \multicolumn{3}{|c|}{$\begin{array}{l}\text { Hortonian excess flow only } \\
\text { (conventional approach) }\end{array}$} & \multicolumn{3}{|c|}{$\begin{array}{l}\text { Contribution from both infiltrated } \\
\text { rainfall and Hortonian excess } \\
\text { flows (suggested approach) }\end{array}$} \\
\hline & & $E^{\mathrm{a}}$ & $\begin{array}{l}\text { Peak } \\
\text { ratio }^{b}\end{array}$ & $\begin{array}{l}\text { Volume }^{\mathrm{c}} \\
\left(10^{6} \mathrm{~m}^{3}\right)\end{array}$ & $E$ & $\begin{array}{l}\text { Peak } \\
\text { ratio }^{b}\end{array}$ & $\begin{array}{l}\text { Volume }^{c} \\
\left(10^{6} \mathrm{~m}^{3}\right)\end{array}$ \\
\hline 1 & $2007-04-25$ & 0.89 & 0.86 & 1.5 & 0.70 & 0.79 & 1.7 \\
\hline 2 & $2007-08-22$ & 0.21 & 1.18 & 1.6 & 0.47 & 1.05 & 2.3 \\
\hline 3 & 2008-01-07 & 0.70 & 0.96 & 2.3 & 0.92 & 0.97 & 2.9 \\
\hline 4 & 2009-04-27 & 0.72 & 0.90 & 1.4 & 0.90 & 0.70 & 1.6 \\
\hline
\end{tabular}

${ }^{\mathrm{a}}$ Nash-Sutcliffe model efficiency; ${ }^{\mathrm{b}} Q_{\max , \text { observed }} / Q_{\max \text {,simulated }} ;^{\mathrm{c}}$ total volume of the discharge.
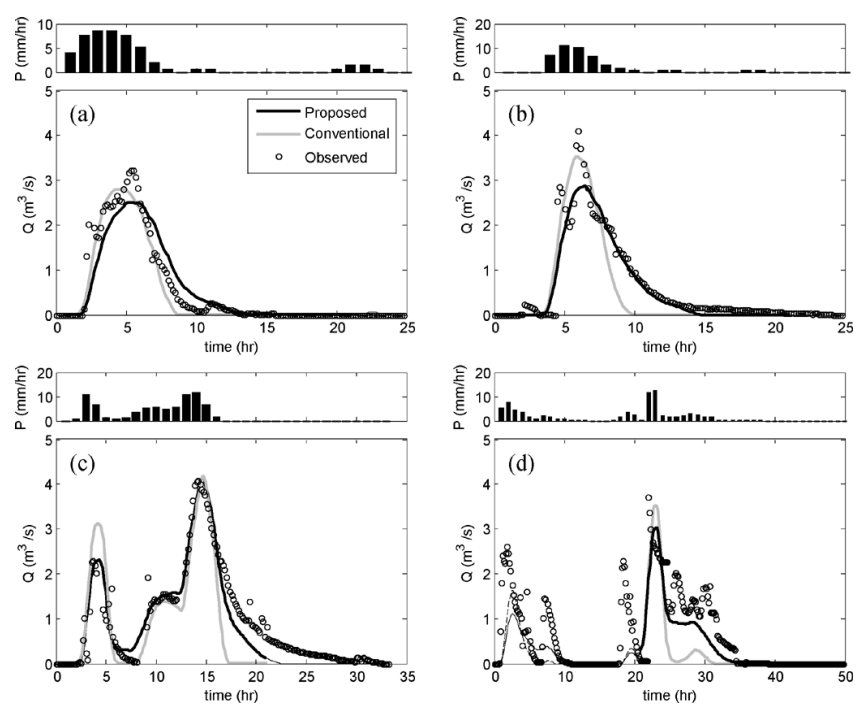

Fig. 6. Comparison of the conventional (considering Hortonian excess runoff only) and proposed (considering both Hortonian excess runoff and infiltrated rainfall) approaches with the observed hydrographs for the storms in (a) April 2007, (b) August 2007, (c) January 2008, and (d) April 2009.

terms of the flow peak as well as the long tail observed in the hydrograph (Fig. 7b). The hydrographs from the conventional approach and the IUHM are almost identical (Fig. 7b), which indicates that the performance of the conventional approach utilizing a width function is comparable with the IUHM. Therefore, it implies that the performances of other models considered in this study can be greatly improved and
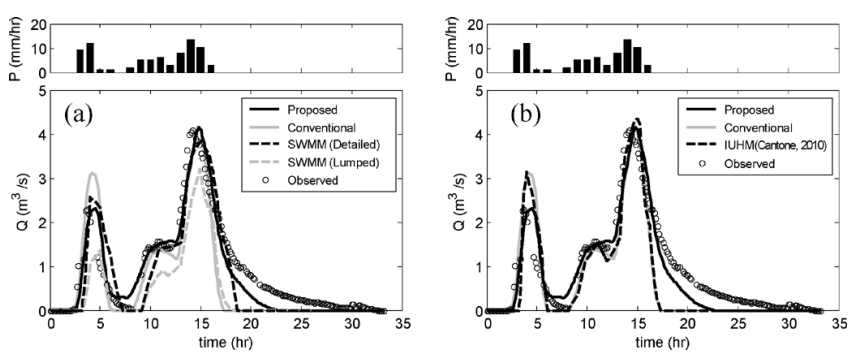

Fig. 7. Comparison of the conventional and proposed approaches with the observed hydrographs and (a) EPA SWMM model, (b) IUHM (Cantone, 2010) for the 2008 January storm.

possibly better perform better compared with the proposed approach in this study by considering the effect of the infiltrated amount of rainfall in pervious areas. However, the width function based approach stands out with the ability of discriminating pervious area from impervious area in urban catchments. The proposed method, WFIUH, in this study is a semi-distributed approach utilizing a width function. Therefore, it enables us to consider the spatial variability of precipitation as well as catchment properties, such as soil properties, land use, and imperviousness, which is an advantage of WFIUH compared to IUHM.

\subsection{Quantifying the contributions from pervious and impervious areas to the runoff hydrographs}

The modeling framework in urban catchments proposed in this study is able to quantify and differentiate the 

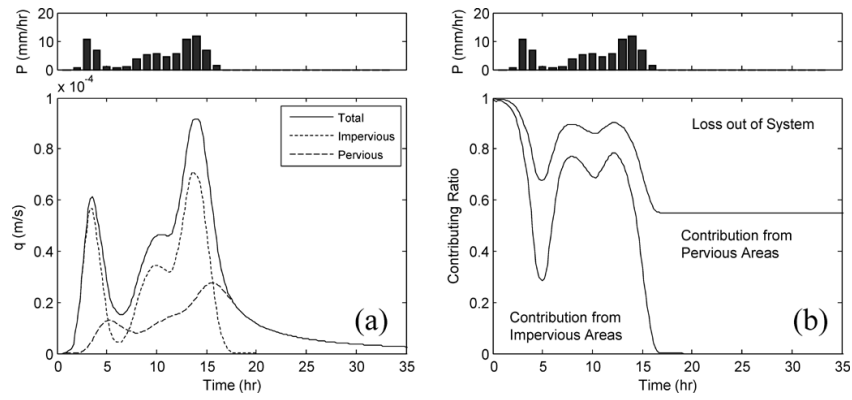

Fig. 8. Contribution from pervious and impervious areas for the storm in January 2008: (a) hydrographs for each region, (b) contributing ratio to total flow
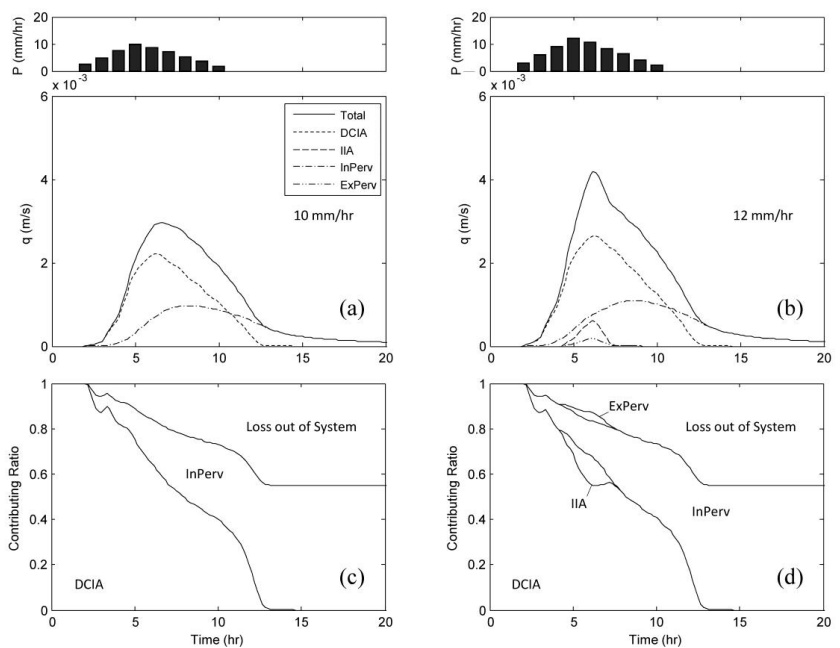

Fig. 9. Flow discharge per unit area in CDS-51 with a triangular hyetograph and maximum intensity of (a) $I=10 \mathrm{~mm} \mathrm{~h}^{-1}$, (b) $I=12 \mathrm{~mm} \mathrm{~h}^{-1}$ and the contributing ratio of each area with (c) $I=10 \mathrm{~mm} \mathrm{~h}^{-1}$, (d) $I=12 \mathrm{~m} \mathrm{~h}^{-1}$.

contributions from pervious and impervious areas. Figure 8a illustrates the contribution of pervious and impervious areas to total flow with time for the storm event in January 2008 (event 3). The contribution from each area changes with time. For a short duration after the storm event starts, the contribution from impervious areas dominates; then, the contribution from pervious areas starts to dominate afterwards. Figure $8 \mathrm{~b}$ illustrates the variation of the contributing ratio with time. In order to quantify the contribution of the pervious and impervious areas to the runoff hydrographs in detail, additional model runs are performed with test rainfall events of a synthetic triangular hyetograph for CDS-51. The two test events have the same duration of $10 \mathrm{~h}$ but different maximum intensities of the rainfall; $10 \mathrm{~mm} \mathrm{~h}^{-1}$ with no excess rainfall and $12 \mathrm{~mm} \mathrm{~h}^{-1}$ with excess rainfall. The contribution of DCIA, IIA, ExPerv and InPerv can be separately quantified by Eq. (23). Figure 9 depicts the resulting flow discharges per unit area of DCIA, IIA, InPerv, and ExPerv, respectively.
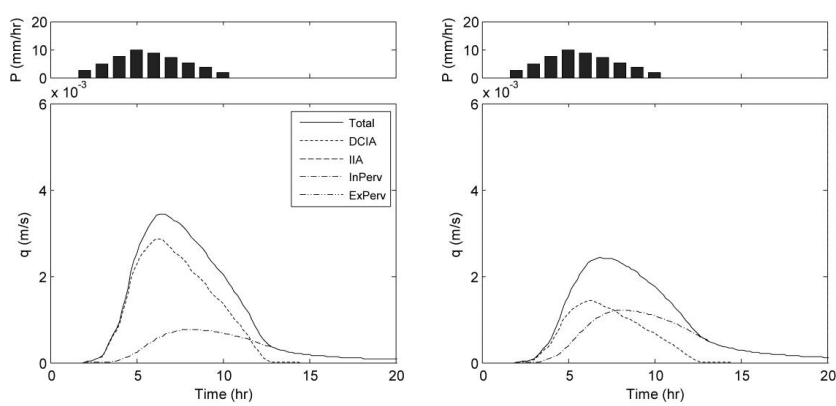

Fig. 10. Flow discharge per unit area in CDS-51 with a triangular hyetograph and maximum intensity of $10 \mathrm{~mm} \mathrm{~h}^{-1}$ when (a) $r_{c}=0$, (b) $r_{c}=0.5$.
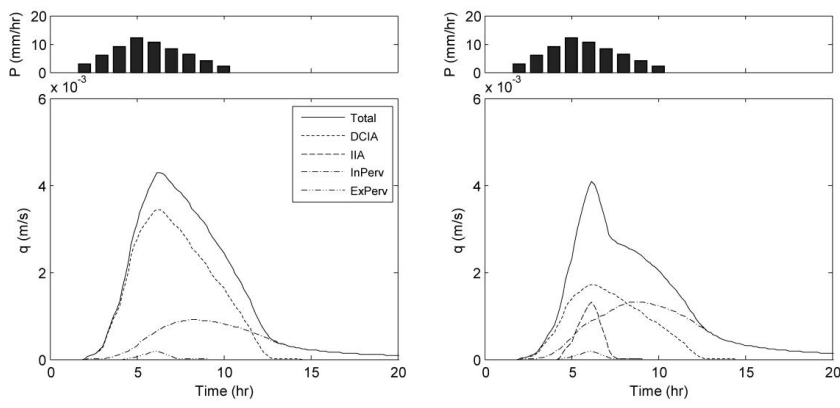

Fig. 11. Flow discharge per unit area in CDS-51 with a triangular hyetograph and maximum intensity of $12 \mathrm{~mm} \mathrm{~h}^{-1}$ when (a) $r_{c}=0$, (b) $r_{c}=0.5$.

The results illustrate how the contribution ratio of each area changes with rainfall intensity and time. The results show that the contribution from DCIA dominates initially while the contribution from InPerv slowly increases with time. The contribution from DCIA shortly diminishes after the rainfall stops. While the contribution from InPerv responds slowly and consequently results in a longer tail. The slow response from InPerv mainly contributes to the long tail of the total discharge hydrograph. Before excess rainfall occurs, ExPerv and IIA do not contribute to flow discharge and the hydrograph is composed of contributions from DCIA and InPerv only (Fig. 9a). Once excess rainfall occurs, InPerv and IIA start to contribute to the total runoff hydrograph (Fig. 9b). The contribution of DCIA, IIA, and ExPerv grows at rates that are proportional to corresponding areas with increasing rainfall intensity.

IIA affects the runoff hydrograph especially before saturation occurs. Figure 10 compares the flow discharge per unit area with a synthetic triangular hyetograph with or without IIA. In case of IIA not being considered, impervious area (IA) is composed only with DCIA. When there is no IIA $\left(r_{c}=0\right)$ (Fig. 10a), all impervious areas are regarded as DCIA, which involves immediate response to the flow. However, when IIA composes $50 \%$ of IA $\left(r_{c}=0.5\right)$, IIA does not contribute to the runoff hydrograph because the rainfall 
falling on IIA infiltrates before saturation occurs. As a result, Fig. 10b shows a reduced peak discharge and a thick and long tail compared with Fig. 10a, in which IIA is ignored. When the soil saturates and excess rainfall occurs, rainwater in IIA as well as saturated pervious areas (ExPerv) starts to contribute to the runoff hydrograph (Fig. 11b). Once saturation occurs and rainwater in ExPerv and IIA start to contribute to the runoff hydrograph, all the areas contribute to produce runoff. As shown in Fig. 11a and b, the peaks of the hydrograph do not show much difference in case of rainfall intensity as $12 \mathrm{~mm} \mathrm{~h}^{-1}$. However, IIA affects the shape of the hydrograph and also produces a thick and long tail compared to the case when it is ignored.

\section{Conclusions}

In this paper, WFIUH is adapted to account for the contribution of distinct pervious and impervious areas utilizing the spatial distribution of the imperviousness areas in an urban catchment. Accounting for pervious and impervious areas separately enables one to see the unique hydrodynamic properties for each contribution. This study introduces two assumptions regarding pervious area contribution to the hydrograph. First, a portion of infiltrated rainfall in pervious areas contributes to the runoff hydrograph before excess rainfall occurs. Second, rest of the infiltrated rainfall is lost out of the system. An explanation of the observed hydrograph can be improved significantly under this framework. Specifically, the suggested approach is able to reproduce the long tails observed in the urban runoff hydrograph, which could not be explained by the conventional approach that does not consider the contribution of infiltrated rainfall in pervious areas. The results show that as much as $55 \%$ of the infiltrated water eventually contributes to the direct runoff hydrograph in an urban catchment. The ratio of infiltrated water implies the characteristics and conditions of the combined sewage system, such as aging, illegal connections, drain material, and fractures of the conduits.

Based on the two simple assumptions for pervious areas, this study also distinguishes the contribution from DCIA and IIA. By introducing DCIA and IIA, and dividing the runoff contribution from pervious areas into two components: infiltrated rainfall (InPerv) and excess rainfall (ExPerv), it was possible to quantify the contribution of each area. As a result, this approach shows the important role of IIA in that it reduces the direct runoff contribution from impervious areas to the total runoff hydrographs. In spite of the efforts to include the contribution of the infiltrated rainfall, this study still relies on an assumption of an inverse Gaussian travel time distribution, which is one of many other possibilities. Also, it should be noted that the pressurized condition, when conduits are surcharged, is not incorporated in this study. This study left the examination of other possible characteristic response functions to future study. However, the framework of this study strongly suggests the flow contribution from pervious areas to the total runoff hydrograph in urban areas is significant. Consequently, it shows that runoff prediction should account for the flow paths from pervious areas to the main drainage network in urban catchments.

Acknowledgements. This research was supported by the Metropolitan Water Reclamation District of Greater Chicago, and also by a grant from the Construction Technology Innovation Program (11-Tech-Innovation-C06) initiated by the Ministry of Land, Transportation and Maritime Affairs (MLTM) of the Korean government. The authors thank Joshua P. Cantone for providing SWMM simulation results as references.

Edited by: N. Basu

\section{References}

Bear, J.: Dynamics of fluids in porous media, xvii, 764 pp., Dover, New York, 1988.

Booth, D. B. and Jackson, C. R.: Urbanization of aquatic systems: degradation thresholds, stormwater detection, and the limits of mitigation, J. Am. Water Resour. As., 33, 1077-1090, 1997.

Boyd, M. J., Bufill, M. C., and Knee, R. M.: Pervious and impervious runoff in urban catchments, Hydrolog. Sci. J., 38, 463-478, 1993.

Brabec, E., Schulte, S., and Richards, P. L.: Impervious Surfaces and Water Quality: A Review of Current Literature and Its Implications for Watershed Planning, J. Plan. Lit., 16, 499-514, 2002.

Butler, D. and Davies, J. W.: Urban drainage, 2nd Edn., xxii, 543 pp., Spon Press, London; New York, 2004.

Cantone, J. P.: Improved understanding and prediction of the hydrologic response of highly urbanized catchments through development of the Illinois Urban Hydrologic Model (IUHM), University of Illinois at Urbana-Champaign, Urbana, IL, 2010.

Cantone, J. P. and Schmidt, A.: Improved understanding and prediction of the hydrologic response of highly urbanized catchments through development of the Illinois Urban Hydrologic Model, Water Resour. Res., 47, W08538, doi:10.1029/2010WR009330, 2011.

Cantone, J. P., Schmidt, A. R., Hollander, M., Erickson, A., Tang, Y., and Garcia, M. H.: Application of the Illinois Urban Hydrologic Model (IUHM) to selected catchments in the Calumet Tunnel and Reservoir Plan SystemRep., 94 pp., Ven Te Chow Hydrosystems Lab, Department of Civil and Environmental Engineering, University of Illinois at Urbana-Champaign, Urbana, IL, 2009.

Crobeddu, E., Bennis, S., and Rhouzlane, S.: Improved rational hydrograph method, J. Hydrol., 338, 63-72, 2007.

Crosa Rivarola, C. S.: High resolution synthetic urban watershed data for hydrologic model evaluation, M.S. thesis, viii, 129 leaves, University of Illinois at Urbana-Champaign, 2008.

Da Ros, D. and Borga, M.: Use of digital elevation model data for the derivation of the geomorphological instantaneous unit hydrograph, Hydrol. Process., 11, 13-33, 1997.

De Benedittis, J. and Bertrand-Krajewski, J. L.: Measurement of infiltration rates in urban sewer systems by use of oxygen isotopes, Water Sci. Technol., 52, 229-237, 2005. 
Di Lazzaro, M.: Regional analysis of storm hydrographs in the Rescaled Width Function framework, J. Hydrol., 373, 352-365, 2009.

EPA: Estimating change in Impervious Area (IA) and Directly Connected Impervious Areas (DCIA) for Massachusetts Small MS4 Permit Rep., US Environmental Protection Agency, Washington, 2011.

Fetter, C. W.: Applied Hydrogeology, Prentice Hall PTR, 2001.

Franchini, M. and O'Connell, P. E.: An analysis of the dynamic component of the geomorphologic instantaneous unit hydrograph, J. Hydrol., 175, 407-428, 1996.

Gironas, J., Niemann, J. D., Roesner, L. A., Rodriguez, F., and Andrieu, H.: A morpho-climatic instantaneous unit hydrograph model for urban catchments based on the kinematic wave approximation, J. Hydrol., 377, 317-334, 2009.

Green, W. H. and Ampt, G. A.: Studies on soil physics, part I, the flow of air and water through soils, J. Agr. Sci., 4, 1-24, 1911.

Gregory, J. H., Dukes, M. D., Jones, P. H., and Miller, G. L.: Effect of urban soil compaction on infiltration rate, J. Soil Water Conserv, 61, 117-124, 2006.

Gupta, V. K. and Waymire, E.: On the formulation of an analytical approach to hydrologic response and similarity at the basin scale, J. Hydrol., 65, 95-123, 1983.

Gupta, V. K., Waymire, E., and Wang, C. T.: A representation of an instantaneous unit-hydrograph from geomorphology, Water Resour. Res., 16, 855-862, 1980.

Han, W. and Burian, S.: Determining Effective Impervious Area for Urban Hydrologic Modeling, J. Hydrol. Eng., 14, 111-120, 2009.

Huber, W. C. and Dickinson, R. E.: Storm Water Management Model, Version 4: User's Manual, Environmental Research Laboratory, Office of Research and Development, US Environmental Protection Agency, Athens, GA, 1992.

Lashermes, B. and Foufoula-Georgiou, E.: Area and width functions of river networks: New results on multifractal properties, Water Resour. Res., 43, W09405, doi:10.1029/2006WR005329, 2007.

Lee, M. T. and Delleur, J. W.: A variable source area model of the rainfall-runoff process based on the Watershed Stream Network, Water Resour. Res., 12, 1029-1036, doi:10.1029/WR012i005p01029, 1976.

Lee, J. G. and Heaney, J. P.: Estimation of urban imperviousness and its impacts on storm water systems, J. Water Res. Pl.-ASCE, 129, 419-426, 2003.

Mejia, A. I. and Moglen, G. E.: Impact of the spatial distribution of imperviousness on the hydrologic response of an urbanizing basin, Hydrol. Process., 24, 3359-3373, 2010.
Mesa, O. J. and Mifflin, E. R. (Eds.): On the relative role of hillslope and network geometry in hydrologic response, 1-17, D. Reidel, Dordrecht, 1986.

Miller, K., Oberg, N., Catano, Y. A., Choi, N.-J., Cantone, J., Seo, Y., Schmidt, A. R., and Garcia, M. H.: Quarterly progress report for phase I modeling of the Calumet and Mainstream/Des Plaines TARP systems and Phase II modeling of the Calumet TARP system, Rep., Van Te Chow Hydrosystems Lab., Dep. of Civil and Environment Engineering, University of Illinois at UrbanaChampaign, Urbana, IL, 2009.

Moussa, R.: Effect of channel network topology, basin segmentation and rainfall spatial distribution on the geomorphologic instantaneous unit hydrograph transfer function, Hydrol. Process., 22, 395-419, 2008.

Naden, P. S.: Spatial variability in flood estimation for large catchments - the exploitation of channel network structure, Hydrolog. Sci. J., 37, 53-71, 1992.

Nash, J. E. and Sutcliffe, J. V.: River flow forecasting through conceptual models part I - A discussion of principles, J. Hydrol., 10, 282-290, 1970.

Rodriguez-Iturbe, I. and Valdes, J. B.: Geomorphologic structure of hydrologic response, Water Resour. Res., 15, 1409-1420, 1979.

Roy, A. H. and Shuster, W. D.: Assessing Impervious Surface Connectivity and Applications for Watershed Management, J. Am. Water Resour. As., 45, 198-209, 2009.

Strahler, A. N.: Quantitative analysis of watershed geomorphology, EOS T. Am. Geophys. Un., 38, 913-920, 1957.

Troutman, B. M. and Karlinger, M. R.: Unit-hydrograph approximations assuming linear flow through topologically random channel networks, Water Resour. Res., 21, 743-754, 1985.

Vaes, G., Willems, P., and Berlamont, J.: Filtering methods for infiltration flow quantification, 10th International Conference on Urban Drainage, Copenhagen, Denmark, 2005.

Van de Nes, T. J.: Linear analysis of a physically based model of a distributed surface runoff system, Centre for Agricultural Publishing and Documentation, Wageningen, the Netherlands, 1973.

Walsh, C. J., Fletcher, T. D., and Ladson, A. R.: Stream restoration in urban catchments through redesigning stormwater systems: looking to the catchment to save the stream, J. N. Am. Benthol. Soc., 24, 690-705, 2005.

Weiss, G., Brombach, H., and Haller, B.: Infiltration and inflow in combined sewer systems: long-term analysis, Water Sci. Technol., 45, 11-19, 2002.

Yen, B. C. and Akan, A. O.: Hydraulic design of urban drainage systems, in: Hydraulic design handbook, edited by: Mays, L. W., McGraw-Hill, New York, 1999. 